\title{
Contested histories, participatory movements and the making of memories in Bangladesh
}

\author{
Meghna Guhathakurta \\ Executive Director, Research Initiatives, \\ Bangladesh \\ meghna.guhathakurta@gmail.com
}

\begin{abstract}
The following is the text of the 2016 Prato Conference Keynote presentation.
\end{abstract}

The seventies witnessed the birth of a new nation called Bangladesh amidst much bloodshed and violence. The belief that accompanied the culture of a newly independent state in 1971 was commonly perceived as Sonar Bangla (Golden Bengal). It was believed that once the hardships of the struggle for an independent Bangladesh were over, the country would undergo economic emancipation. This was also reflected in the constitution which was built on the four pillars of Nationalism (i.e. Bengali nationalism based on language), socialism defined in terms of welfare for all, Democracy and Secularism ( meant more as equal emphasis and tolerance of all religion. But the reality turned to be very different. The aftermath of independence, gave birth to a ruling class that had absolute majority but was not hegemonic their power base resting predominantly on the petit bourgeois and the rural rich. This class did not have influence over the military-bureaucratic oligarchy which had traditionally controlled the 'over developed' Pakistan state. In this way the class which received state patronage procured jobs in the nationalized industries, grew rich by appropriating privileges bestowed upon them by the state. As a consequence the military coup d'etat which

Guhathakurta, M. (2017). Contested histories, participatory movements and the making of memories in Bangladesh (Keynote paper for the Prato conference, 2016). The Journal of Community Informatics, 13(2), 8-12.

Date submitted: 2017-08-20. Date accepted: 2017-08-25.

Copyright (C), 2017 (the author as stated). Licensed under the Creative Commons AttributionNonCommercial-ShareAlike 2.5. Available at: www.ci-journal.net/index.php/ciej/article/view/1416 
toppled the government in 1975 represented to a large extent a section of the militarybureaucratic oligarchy that had enjoyed political privileges and patronage of the state in the past and felt deprived in the newly independent Bangladesh.

The military coup by General Ershad in March 1982 led to the creation of an authoritarian military bureaucratic state. Parties were created from the cantonment to legitimize military rule. Lacking an overarching ideology with which to attract popular support and legitimacy attempt was made to use religion, thus making Islam the state religion. We thus see the Bangladesh nation state veering away from its original constitutional foundations of secularism, democracy and socialism.

But the people of Bangladesh did not lose heart. After much soul searching throughout the eighties they coalesced together into the anti-autocracy movement from 1987 culminating in 1990 resulting in the collapse of the military regime and the ensuing elections of 1991, which brought back parliamentary democracy to the political arena, demonstrated the strength of the civil society in Bangladesh.

But the aftermath of the movement and the consequent nature of Bangladesh politics proved that unresolved issues remained in the political scenario even after a freely elected government came into power with promises for a democratic future. These were the rise of Islamic fundamentalist forces, in more recent years terrorist trends. The fight against the fundamentalists have had its ups and down as both the establishment and the opposition parties decided to use it as a third force in their fight against each other.

Furthermore successive governments have failed to address the questions of economic emancipation for the common citizen. It was not likely that the principles of secularism and socialism, which got struck off the Constitution was likely to make its way back again very easily, particularly not in a world where integration to the world economy counted more as survival strategy than as an economic option, nor in a region where the prospect of religious fundamentalism coupled with its potency for capturing state power, overpowered and made inadequate liberalist visions and options of statecraft.

\section{Participatory Movements}

But peoples' politics or indeed economics or democracy were not only to be engaged at the level of principles or for that matter structure and institutions such as electoral systems and restricting of election commissions or political parties. What one tends to forget are the day to day struggles of people who are trying to take control of their lives. These are the people who mattered, the people who are inscribed into the words "Gonoprojatronti" (Peoples' Republic) before the name of Bangladesh. Do the leaders of democracy ever recognize them? Are electoral rolls enough to make them captains of their own fate? The answer is an obvious no. Rather, in the political discourse of parties they become the 'masses', in the development discourse, they become the illiterate, in the economic discourse, the recipients or beneficiaries. Never are they perceived as the thinking and creative beings that they are, the true 'demos' of democracy. 
If we take a broader picture of what politics is we may begin to think differently. According to Adrian Leftwich, politics have been defined as that which.... "comprises all activities of cooperation and conflict within and between societies, whereby the human species goes about organizing the use, production and distribution of human, natural and other resources in the course of production and reproduction of its biological and social life." In other words politics is not only about elections and votebanks, power-play and dominance. It is about how people individually, collectively and organizationally use, produce and distribute resources, material and non-material for the betterment of their being. It is about how and why a farmer's cooperative allocates resources in the way it does just as much as it is about how and why Governments determine the annual budget of a country. It is about how women and men each contribute to the raising of their children, just as much as a government's decision to follow secular or religious ideals. Hence democratizing politics is simply not about reforming electoral rolls and party hierarchies, it is about revisiting and reinventing the 'demos' in ones political agenda. This is true not only for political parties, but also for development organizations, civil society and professional organizations, the media, in short any entity that exists for or seeks to represent the public good. Acceptance of the perspectives of the people themselves is crucial to this understanding. Agronomists have years of schooling behind them true, but farmers have years of experience too. They have direct knowledge of the soil, the water, the lay of the land. It is interesting that once political parties and development organizations all used to go to the people and based their political or development programs on the problems of the locality. Such days are gone. The perspectives of the people have been taken over by party prerogatives on the one hand and institutional ( $\mathrm{NGO}$, and media) prerogatives on the other. Yet if we take a look at the national scene, we see that it is not these parties or institutions which have played a role in the welfare of Bangladesh, it is the countless, nameless people; women and men who have been responsible for it. Farmers have tilled their land, regardless of what benefit they may have got from the state, women have sent their children to school and tried to give them a full meal each day. Children too have done their bit, whether it be combing the beach for shells to sell, or gathering firewood in the forests. They know tomorrow's meal would depend on such activities and they know that the nation, the world would probably forget them or at best pay lip service, but that tomorrow would come anyway and they, their children would like to live to see that day.

Gonogobeshona or people's research is only one way which helps us to rediscover the existential dignity of people. Research Initiatives, Bangladesh used this method mainly in working with the marginalized communities. Gonogobeshona, a term for Participatory Action Research that was coined in the rural villages of Bangladesh, works through stimulating peoples' own collective praxis. It brings out the creativity of people in multiple directions and in a holistic way. Spontaneous participation of people lies at the centre of such methodology. Indigenous and local knowledge and self-analysis are given as much importance as knowledge developed by experts and brought to assist people's action only when considered relevant by the concerned community. This results in a rise in self-confidence so that development processes as indeed political processes remain people-centric. 
Animators play a pivotal role in the process. They are the change agents who stimulate the people into creative action. It is the animators who initiate and demonstrate organizational skills in a combined effort to tackle difficult challenges and bring out the innate and latent creativity of people with regard to problem-solving.. Animators often act as the link between the common people and technical knowledge, skilled or resource persons for example an agricultural expert, an IT technician or a University teacher. An animator can emerge from the group itself or externally. In Bangladesh the process is usually activated through group discussions in village or neighborhood courtyards (currently in urban slums).It works in a way to reach out and generate confidence amongst community members and enables them to engage in individual and collective self-development in an environment of trust. In the practice of gonogobeshona both the individual and collective are important to reach a decision. They follow the path of selfdevelopment by collectively utilizing their knowledge in an unfavourable environment. Indigenous women prevent their cemeteries from being grabbed by the Forestry Department, Mundas who live off forests fight to keep their identities even when displaced by storm surges and tornadoes, refugees argue not only for basic services, but the right to develop their own language. Gonogobeshona therefore first transforms the self and then affects the larger collective and as such plays a crucial role in the making of sustainable memories for a new generation. What are these memories?

\section{The Making of Memories}

The intensity in which the centenary of the World War I seems to be remembered in England does not seem to be as profoundly celebrated in other countries, although by its very definition it was a World War! On the other hand in Bangladesh, a young generation who had not witnessed the Liberation War of 1971 was demanding the punishment for war criminals! Many western diplomats were left wondering, why it was being articulated by the younger generation, those potential yuppies, who should be thinking about furthering their careers in the global rat race, falling in love and getting married or simply chilling out in the newest coffee joint in town; not thinking of what happened 40 years ago! The simple answer was of course the young generation was doing all that and more and yet what happened 40 years ago mattered, because the search for an identity or dignity is a continuous one and one that needs to be worked and reworked by each generation. It does not stop at the making of a Constitution, neither does it get resolved even at the amendment of one. The reworking takes place at a depth of the consciousness that is both individual and collective and hence involves complex processes of both collective memories and individual propensities, not unlike the Gonogobeshona process that I just described.

Let's begin with the collective memories. All too often, collective memories get conflated with national memories or national consciousness. The reasons are obvious. The emergence of the nation-state came with all the power of the state which was deemed to control a unifying process of bringing a nation together ideally under the aegis of one single, broader identity. Those in control of state power use the same marker of consciousness albeit with their own legends and polemics. But as history stands witness such nation-building process are not always inclusive. The long and short 
of it is that collective memory i.e. memories of those not central to the nation-building processes may be very different from the state-sponsored national discourses and debates. They in fact may be broader, more complex and run parallel to or in opposition to national discourses and hence failed to get integrated into it. But that is not to say they do not exist. That is why we see movements, uprisings in different period of time surface, often demanding recognitions of such memories and their consequent realties.

Individual memories through an intricate process of story-telling and legend building which often fit in organically with collective memories help to strengthen respective strands of thought. We witness such individual reminiscences of victims and freedom fighters periodically during national day celebrations, on other days stories of successful women or brave indigenous warriors inform their respective histories. But in the play of power (e.g. those who control the media, education, or broadly speaking production of culture) some stories get valorized over others hence influencing the direction of history.

However, individual memories also have a potential for playing the subversive role of deconstructing some of the collective legends through creative translation inevitably reflected in works of art. Artists in general facilitate the translation of memory or recall of events even decades after that event is over. Masterpieces of films on the World Wars even 100 years on still hold us spell bound not so much as documentation of the events or an informed retelling of history, but as an emotional re connection with events based on principles that transcend time and space; principles such as humanity or a rediscovery of truths which the conscious mind had so far denied or not previously acknowledged.

This is a challenge for us all. It leads us to ask the following questions: are we helping to make memories that touch such principles of humanity or awaken the consciousness of a people that time had long forgotten? Do our technologies allow for the creative criticality of thinking that movements like these may need or are they just confirming existing cultures and establishments? I do believe that these questions will be answered in a multitude of ways by the presentations and deliberations to take place in this conference in the coming days. The themes already speak of a richness of experience as they do of innovative critical approaches. I look forward to participating in such an inspiring dialogue. 